This item was submitted to Loughborough's Research Repository by the author.

Items in Figshare are protected by copyright, with all rights reserved, unless otherwise indicated.

\title{
Factors influencing experience in crowds - the participant perspective
}

\section{PLEASE CITE THE PUBLISHED VERSION}

http://dx.doi.org/10.1016/j.apergo.2016.09.009

\section{PUBLISHER}

(c) Elsevier

\section{VERSION}

AM (Accepted Manuscript)

\section{PUBLISHER STATEMENT}

This work is made available according to the conditions of the Creative Commons Attribution-NonCommercialNoDerivatives 4.0 International (CC BY-NC-ND 4.0) licence. Full details of this licence are available at: https://creativecommons.org/licenses/by-nc-nd/4.0/

\section{LICENCE}

CC BY-NC-ND 4.0

\section{REPOSITORY RECORD}

Filingeri, Victoria, Ken Eason, Patrick Waterson, and Roger Haslam. 2016. "Factors Influencing Experience in Crowds - the Participant Perspective". Loughborough University. https://hdl.handle.net/2134/23408. 
Factors influencing experience in crowds The participant perspective

Victoria Filingeri, Ken Eason, Patrick Waterson, Roger Haslam

Human Factors and Complex Systems, Loughborough Design School, Loughborough University, Leicestershire, LE11 3TU, UK 


\title{
Factors influencing experience in
}

\section{crowds - the participant perspective}

\begin{abstract}
Humans encounter crowd situations on a daily basis, resulting in both negative and positive experiences. Understanding how to optimise the participant experience of crowds is important. In the study presented in this paper, 5 focus groups were conducted (35 participants, age range: 21-71 years) and 55 crowd situations observed (e.g. transport hubs, sport events, retail situations). Influences on participant experience in crowds identified by the focus groups and observations included: physical design of crowd space and facilities (layout, queuing strategies), crowd movement (monitoring capacity, pedestrian flow), communication and information (signage, wayfinding), comfort and welfare (provision of facilities, environmental comfort), and public order. It was found that important aspects affecting participant experience are often not considered systematically in the planning of events or crowd situations. The findings point to human factors aspects of crowds being overlooked, with the experiences of participants often poor.
\end{abstract}

Keywords: Crowds, Participant experience, Satisfaction 


\section{Introduction}

Gatherings of people (hereafter referred to as crowds) form part of our everyday human experience. Commonplace activities such as commuting to work via transport hubs or shopping in retail environments, social occasions such as visiting bars and restaurants, or entertainment situations (e.g. music festivals, football matches, theme parks and museums) are all examples of crowd environments. Altman (1975) suggested that research into crowds would increase over the next decade due to 'a burgeoning world population' and the 'interpersonal stresses that accrue from too much contact with too many people'. Despite Altman's predictions, however, research into crowd experience remains surprisingly underdeveloped, particularly with regard to achieving a positive experience for crowd participants (crowd users).

The term 'crowd' can have connotations ranging from negative through positive. A situation can be regarded as crowded when the density is such that it obstructs the performance and goal achievement of individuals (Sundstorm, 1978; Eroglu \& Machleit, 1990). A negative experience of crowding has been described as a consequence of physical, social and personal factors that "sensitise the individual to actual or potential problems arising from scarce space" (Stokols, 1972). Individuals will perceive the same crowd with a different level of stress depending on their personal tolerance (Stokols, 1972; Whiting and Nakos, 2008). Although high-density situations contribute to a negative experience for some individuals in particular circumstances, there may be positive outcomes for others, known as functional density (Eroglu \& Harrell, 1986; Yildirim \& Akalin-Baskaya, 2007; Pons et al., 2015). The atmosphere experienced at a capacity sporting event is an example where the crowd and crowding can contribute to an enjoyable experience.

Arousal theory suggests a curvilinear effect between density and satisfaction, with high and low levels of a arousal leading to a negative experience, and medium arousal leading to a positive experience (Seyle, 1956, Hebb, 1972; Evans \& Lepore, 1992; Singh, 1998). However, this is context dependant and cannot account for the enjoyment of very high-density situations such as 'mosh pits' seen at some music events for example. Mowen et al. (2003) provide further support for a functional relationship between density and satisfaction in relation to festival environments, where a low density might reflect a poor event. Whiting and Nakos (2008) compared 
the effects of high, medium and low density environments, under different situational contexts (i.e. individuals at a baseball game), and found that medium density situations had the potential to produce positive outcomes instead of negative outcomes. Culture was also identified as contributing to individual perceptions of density preference, an important consideration with international crowd environments.

The majority of crowd-related research has focused on safety and security aspects. This has included pedestrian flow and its modelling (Smith et al., 2009; Still, 2013; Kim et al., 2015; Liu et al., 2016) and public order policing (Reicher et al., 2004; Stott et al., 2008; Drury \& Stott, 2011). This research emphasis has followed on from major crowd incidents, e.g. the disasters related to pilgrimages to the Hajj in Saudi Arabia (Hughes, 2003), or the 1989 Hillsborough sports stadium disaster in the UK (Davis et al., 2014).

The Hillsborough Independent Panel (2012) identified a number of crowd management issues as contributing to the disaster, including: inadequate management of the crowd by police and stewards, and a mindset primarily concerned with crowd disorder; a lack of leadership and co-ordination; and a lack of precise monitoring of crowd capacity within the stadium. The "frustration and desperation" displayed by participants in the crowd was incorrectly observed by police and stewards as disorder and antisocial behaviour. Similar mistakes were evident at previous large-scale events, but lessons had not been learnt, highlighting the importance of continually improving the organisation and planning of crowd events. Also reflecting on Hillsborough, Davis et al (2014) advocated a sociotechnical systems approach for analysing crowd behaviours, highlighting six aspects that should be analysed: goals, people, buildings and infrastructure, technology, culture, processes and procedures. Within the six areas the framework highlighted a number of contributory factors leading to the Hillsborough disaster, including 'lack of communication with the crowds [from the authorities]' and 'lack of coordination across event locations [between the authorities]" (processes), 'lack of leadership' (people), 'inappropriate layout of event environments' (buildings), and 'overreliance on technology' (technology) (Challenger and Clegg, 2011; Davis et al. 2014). Davis et al argued that socio-technical systems thinking would be beneficial in facilitating wider crowd planning and management, as a means of highlighting potential 
problems before an event as well as being of value for evaluation and learning afterwards.

Ryan et al (2010) examined visitor satisfaction for a theme park in Taiwan and found the main sources of satisfaction to be those associated with the atmosphere of the park, the existence of thrill rides, degrees of crowding experienced, having places to rest and a perceived reasonable entry price. Brown and Hutton (2013) considered the psychosocial aspects of audiences at planned events and identified understanding of user motivations, predispositions and behaviour as central to creating a positive "event experience" for crowd participants. Yoon et al. (2010) suggested that through understanding the experience of participants in crowds (i.e. festivals), organisers can efficiently and effectively create a more appealing event. The positive impact of enhancing the participant experience in crowds will aid repeat visitation; increase understanding of the quality dimensions geared to the target market; monitor value and satisfaction to revise the marketing mix accordingly and; consequently increase repeat visitation or loyalty. However, what are the likely repercussions of failing to achieve a positive experience for participants in the crowd? A poor experience for participants could potentially lead to a number negative issues for stakeholders, including: loss of return business; reduced sales of merchandise at the event; diminished reputation of the venue (e.g. for being well organised); antisocial behaviour of frustrated participants (e.g. climbing barriers); misuse and overloading (of facilities, materials and structures); and fire risks amplified if egress impaired.

From a crowd management perspective, Berlonghi (1995) summarised several ways of distinguishing and assessing crowds with respect to event planning. Berlonghi suggested that failure to differentiate between different crowd types could contribute to ineffective management of the crowd. Challenger et al (2010) similarly stressed the importance of distinguishing between different crowd types. Rowe and Ancliffe (2008) suggested that a number of factors are not taken sufficiently into account during the design phase of crowd planning. Within a systems framework, these authors argued that designers traditionally concentrate on the 'environment' (e.g. the building) and 'technology' (e.g. signage) elements. Whereas the operators involved with the crowd situation itself tend to focus on 'process' and 'people' aspects. Rowe and Ancliffe argued that attention to these four aspects needs to be joined up and 
integrated to avoid discrepancies between designers and operators contributing to difficulties for crowd participants.

Other than the safety and security aspects of crowds, which have been well researched, guidance on crowd planning and management is mostly derived from experience and intuition rather than research evidence. Moreover, guidance tends to approach the issue from a design, planning and operational viewpoint, with less attention given explicitly to the participant experience. The motivation for the research presented in this paper, therefore, was to address this through investigations with crowd participants and study of crowd situations. The aims were to identify aspects that contribute to a positive experience of crowds, as well as areas of crowd and event organisation that could be improved for the benefit of crowd participants.

\section{Methods}

Adopting a qualitative approach, initial focus groups were conducted to collect indepth accounts of the aspects of crowd situations important to crowd participants, addressing safety, goal performance, comfort and satisfaction (Kreuger and Casey, 2000). Second, crowd observations were undertaken to examine how crowd situations exist and operate in practice, including attention to aspects identified from the focus groups. Observation research has been used widely in studies of human behaviour and human system interaction, providing ecological validity for issues that cannot be replicated in a laboratory (Bryman, 2004).

For both studies, structured convenience sampling was used (Bryman, 2004). This aimed to include a wide range of individuals and events relevant to and meaningful for understanding the experience of users within a crowd. Sample size for each study was determined through data saturation; i.e. recruitment ended when novel material and insights from the thematic analysis of transcripts and observation records no longer emerged (Straus and Corbin, 1998).

Both studies complied with the requirements of Loughborough University Ethical Advisory Committee. 


\subsection{Crowd user focus groups}

Five focus groups were recruited, with a total of 35 participants (Table 1). Each focus group comprised between 6 and 8 individuals, with the same facilitator conducting each focus group (lasting approximately $90 \mathrm{~min}$ ) in the UK. During each session, a set of photographs was presented to prompt discussion regarding being in a variety of crowd situations (Eroglu \& Machleit, 1990). Photographs were clustered into five different crowd situations: spectator events (music, sporting, and theatre), conferences and exhibitions, transport hubs, participatory events (races, marathons), and retail. Focus group members were invited to discuss each photograph in turn, considering issues they felt would impact their experience within each crowd situation. The focus group discussions were recorded with participants' consent and subsequently fully transcribed.

\section{- Insert Table 1 about here -}

\subsection{Crowd observations}

Crowd observations were undertaken with the researcher observing the crowd as a participant (participant observation) (Bryman, 2004). The same researcher undertook all participant observations. A standardised checklist for structuring the observations was devised, based on analysis of focus group data (Table 2). The checklist was used as a prompt to the researcher for taking audio notes (dictaphone), video recordings and photographs, enabling crowd situations to be observed consistently and systematically. The checklist was piloted with five events and modified iteratively to form the final version. Field notes were taken from the audio and video recordings (in the form of written transcripts) within 24 hours of each observation, to ensure the fidelity of the information (Hancock \& Szalma, 2004).

- Insert Table 2 about here - 
A total of 55 crowd situations were observed covering a wide variety of event types (Table 3), encompassing the following crowd types: ambulatory (walking), spectator (watching an activity or event), expressive (emotional release, shouting, chanting), and restricted movement (Berlonghi, 1995). Moreover, events were sampled to incorporate operational variation seen across different crowd events (identified by Berlongi, 1995): size of the crowd, crowd capacity, demographics of the crowd, location of the event, day and time of operations, schedule of event activities, weather conditions, seating arrangements, crowd movement patterns, density of crowd in various locations, and specific operation (transportation, parking, ticket selling for example). Observations were undertaken within the UK, Europe, USA, South America, and the Middle East, allowing cultural influences with crowd situations to be considered. Observations covered a range of seasons and weather conditions.

\section{- Insert Table 3 about here -}

\subsection{Analysis}

Qualitative analysis of focus group transcripts and event observation data (field notes, video recordings and photographs) followed a systematic, hybrid thematic analysis designed to support the identification, analysis and reporting of themes (as described by Braun and Clarke, 2006). Data transcripts were fully transcribed and analysed on a sentence-by-sentence basis (using qualitative data analysis software NVivo 9). Key themes and patterns within the data were then identified. Analysis was conducted iteratively, with data driven codes developed and emergent overarching themes identified in line with the objectives of the study (Bryman, 2004; Braun and Clarke, 2006). Focus group transcripts were reviewed by each focus group participant to assure correct representation of the material. Reliability was enhanced through the systematic review by two independent researchers, assessing for face validity and consistent coding. 


\section{Results}

The findings of the focus groups and crowd observation studies are complementary and are presented together in the following sections. The findings from both approaches indicated that whilst there were many positive experiences at crowd events, negative experiences were also prevalent. Furthermore, the negative experiences were often similar at different events, repeated in numerous different circumstances, suggesting there are common systemic failures in the way events are planned and organised.

\subsection{0verarching themes}

Analysis of the focus group and event observation data identified five overarching themes for crowd participant experience (see Figure 1).

\section{- Insert Figure 1 about here -}

The major contributor to a positive experience of crowds is enjoyment of the event itself, with the participant having a positive motivation for being there (e.g. a music concert, or sports match). However, there are also many other aspects that can aid or detract from a positive experience, listed in Table 4.

- Insert Table 4 about here -

\subsection{Physical design of crowd spaces and facilities}

The results from both focus groups and crowd observations indicate that the physical design of the environment (crowd spaces and facilities) has important implications for crowd participant experience. 


\subsubsection{Venue layout}

The layout of a crowd venue (planning and arrangement of areas and facilities within a venue, positioning, walkways and space availability) was identified as influencing the experience in crowds. During focus groups, participants discussed frustrations when the layout of a venue created congestion and bottlenecks and feelings of discomfort and anxiety when faced with insufficient space within a crowd. The benefit of sectioned areas was highlighted during the focus group with healthy adults:

"[it is beneficial] when an area is divided and it is segregated so that you don't have thousands of people pushing on you" (Healthy adult: Male aged 51 years)

The design and layout of crowd venues including sectioned areas, seating and clear exit routes were also seen to impact crowd satisfaction during observations. The layout of amenities such as catering facilities and toilets and the handling of the queues to these was a prevalent feature noted during observations. Problems were caused when insufficient space was available between vendor stalls and walkways, impeding individuals passing one another:

"Stalls very close together - small bottleneck areas, crowd members struggle to pass each other. Some people barge past, others get frustrated, and storm past" (Observation: indoor market)

Additionally, when all toilet facilities were situated in one area of a venue, with no systematic queuing this created congestion, whereas placing facilities at various points throughout a venue, or implementing separate queues for each facility dispersed this and reduced user frustration. Placing amenities at a distance from the main event also had beneficial distribution of their users. This emphasizes the extent to which seemingly obvious issues, with simple and inexpensive solutions are not addressed during the planning and running of crowds, leading to poor experiences for participants.

\subsubsection{Queuing problems and strategies}

Queuing was a frequent issue highlighted during the focus groups and observations. This arose with respect to toilets, beverage and food outlets and other amenities, 
with competition between crowd participants and frustration from excessive queue times. During user focus groups one older user gave the following account:

"But again it's just the waiting isn't it? The queuing, the waiting, and the frustration of getting what you want to get. And waiting for people to get out of the way" (Older adult: Female aged 68 years)

During the crowd observations it was apparent that the layout of amenities affected queuing behaviour as seen during a music event in London:

"Separate queues for each toilet created confusion and frustration, as well as competition between crowd users when other crowd users appear to get to a facility before you" (Observation: spectator event)

However, other crowd events appeared to have given more consideration to the use of welfare facilities, for example during another music event in London:

"The separation of the toilets was more structured than at other festivals, with metal barriers in between every 2 toilets, to ensure that people queued in 1 line for 2 toilets. This reduced frustrations between crowd users as the queuing systems seemed fair" (Observation: spectator event)

During the crowd observations a number of different queue management strategies were documented (Figure 2). For many of the crowd events observed, no queuing system was in place, creating high competition between individuals and subsequent antisocial pushing and shoving behaviours. A lack of order also resulted in pressure on staff serving customers, making it difficult for them to keep track of who to serve next, contributing to disputes within an agitated crowd. Additionally, the layout of work stations (e.g. at bars) was often poorly designed for serving staff, increasing queue times due to increased time for staff to complete tasks.

Positive interventions included: having one clear queue separated by queue curlers to clearly distinguish the queue; security personnel at the queue entrance to maintain behaviour; and age identification, such as coloured wrist bands, reducing the time taken for age checks. Additionally, for food and beverage facilities, having a simple, well laid out workstation design, with a small number of menu options, with easy to 
add up prices, aided the efficiency of arrangements, benefitting both customers and staff. Other strategies to reduce queue times included allowing patrons to pre-order drinks to be served during an interval, executive tickets entitling access to additional facilities giving enhanced service reducing the demand elsewhere, and also specified time tickets entitling users to enter the event between specific time slots.

\section{- Insert Figure 2 about here -}

\subsection{Crowd movement}

The focus groups indicated that crowd density and crowd movement (ingress and egress, pedestrian flow) were particular concerns affecting the experience of crowds.

\subsubsection{Monitoring capacity}

Determining the capacity of a crowd situation (e.g. train station, sport stadium, shopping centre), is important in maintaining the safety and comfort of crowd participants. During focus groups, crowd capacity was discussed in relation to personal space preferences, feeling disorientated and the fear of losing accompanying adults or children. Unwelcome close proximity to other people and a lack of sufficient personal space in a crowded environment were commonplace negative experiences. One crowd user expressed dissatisfaction with the lack of space experienced at an event:

"There's like no personal space or anything [when moving through a crowd at an outdoor music event]" (Parent of young children: Male aged 28 years)

Focus group participants also described different personal space tolerance levels across different crowd situations, for example when on a subway train one might expect high density situations and therefore tolerate them, whereas the same high density crowd may not be expected in another crowd situation (e.g. at the supermarket), and therefore tolerance levels may be reduced. 
At a number of the crowd observations, space was found to be insufficient, resulting in experiences such as it feeling oppressive, hot, sweaty and uncomfortable. For example during one outdoor music festival:

"the number of crowd users leaving the site on buses was so high that the queue was extremely claustrophobic and stationary for a number of hours as crowd users gradually forced their way onto buses" (Music festival)

Available space was often insufficient for people with encumbrances, leading to difficulties when carrying luggage or manoeuvring pushchairs in a crowd.

Various approaches were in place to enable staff to monitor the capacity in situations observed, managing crowd numbers including: ticketing for events (including free events), issuing of wristbands for certain areas of a venue, hand stamps and colour coded tickets upon arrival. At an outdoor sporting event, for example:

Tickets were exchanged for wristbands on arrival, colour-coded depending on the stand crowd users were allocated to in order to monitor the capacity across the stadium (Sports event: rugby)

Allocated seating was also used to manage capacity across different areas of one venue, as well as use of entrance and exit points specified on each ticket to manage ingress and egress. Also, information about timings and the presence of clear timetables was important to enable individuals to plan their time, remove confusion and maintain participant satisfaction within a crowd:

"No timings were available to indicate when and where each presentation would take place making it difficult for users to plan their time" (Observation: conferences and exhibitions)

\subsubsection{Pedestrian flow}

Pedestrian flow was discussed during focus groups in relation to the ability to move to a required destination within a venue, with pathways that allowed users to move within the crowd without obstructions and bottlenecks. For example one individual in her focus group emphasised: 
"It is extremely frustrating when the crowd is so dense that you just cannot move, and you just can't get to where you need to be because of all of the people" (Young professional: Female aged 25 years)

During crowd observations a number of problems were noted with regard to pedestrian flow. Obstacles in the pathway and crossed pathways caused visible hindrance for pedestrians. The layout of facilities and design of queuing systems were important for pedestrian flow, with some positioned such that queues crossed into and obstructed pedestrian pathways. For example the following situation was observed at a major city transport hub:

'Ticket machines had been placed next to the information desk, adjacent to the pedestrian flow, forcing queues to merge into the pathway of oncoming pedestrians' (Observation: transport hub)

Additionally, insufficient space allocated for and between pathways created difficulties in the contraflow of individuals, particularly for those with luggage, pushchairs or using wheelchairs:

"Walking through ticket turnstiles with luggage was difficult and required staff assistance to pass through a larger gate creating delays" (Observation: transport hub)

Elsewhere, examples were seen with ample space for pedestrian movement, barriers providing separation between pedestrians moving in opposite directions and use of marshals to guide and keep the crowd moving.

\subsection{Communication of information: signage and wayfinding}

In the focus groups, participants discussed difficulties finding their way around in a crowd situation due to inadequate signage. The benefits of good signage were also highlighted:

"The one good thing with supermarkets is that they have the signs up at the top to tell you where things are. So even if it's crowded and you don't 
know where something is, you can look up and find where to go." (Healthy adult: Female aged 46 years)

During the observations a number of signage issues were noted including: unclear signage, small font sizes, overcomplicated signs that were difficult to understand, flimsy signs that were not fixed securely to the ground, inappropriately placed signs and the absence of signs. Inappropriately placed signage can lead to areas becoming congested and inefficient use of space, as seen during a theatre event:

"A large sign hanging from the ceiling had a large arrow directing crowd users to the right for bar facilities. However no arrow was placed in the opposite direction to another large bar to the left of the sign. Consequently while large queues formed at one bar, crowd users failed to notice the other" (Observation: theatre event)

Complicated section numbering and seating configurations also lead to confusion as individuals attempted to locate their seats:

"AA-JJ (followed by numbers) indicated seating rows on the walls and on the tickets. Crowd users could be seen looking at their tickets, the signs, and the seats in confusion, before asking staff where they should go. Staff members were located next to every door to avoid confusion" (Observation: theatre event)

Good features of signage identified during observations included: use of clear, simple, visible signage, positioned to increase the number of people able to view at one time. Signage was observed at strategic positions along the route to event venues, providing helpful information well in advance. Inside venues, examples were seen of signage installed throughout the location, providing information well matched to the crowd participants' needs and goals.

\subsection{Comfort and welfare}

A number of issues were highlighted affecting the comfort and welfare of crowd participants including the provision of facilities and the effect of environmental factors such as weather conditions. 
Focus group discussions included the importance of adequate provision of welfare facilities (e.g. seating, toilets, water points, food and beverage facilities, sheltered areas). The availability and accessibility of seating and toilet facilities were important to all crowd user groups but particularly older adults (aged over 65). For example, one participant stated:

"You see if you're in the middle of there and you want to go to the toilet that would be a problem" (Older adult: Female aged 70 years).

Additionally another participant suggested:

"There are just never enough toilets at these things [events] especially for the women! So you end up spending half of your time in a queue!" (Healthy adult: Female aged 40)

Observations found the provision of facilities was not always well linked to venue capacity or crowd number, with insufficient numbers leading to long queues and unhygienic facilities.

\subsubsection{Environmental comfort}

Environmental comfort (weather, heat, vision, noise, odours, ventilation, pollution) were found to affect crowd experience. Adverse weather conditions had a negative impact on crowd participant enjoyment, primarily in outdoor situations:

"If the weather's nice, everyone's sort of walking slowly, whereas if it's raining then everyone is going to be walking faster to get out of the rain.... and it's just going to be more of an unpleasant experience." (International student: Female aged 22).

During the observations poor weather conditions included the onset of rain, snow, wind, strong sunshine and extreme heat. As well as directly affecting the participant experience, the weather also interacted with crowd behaviour and the provision of facilities. For example, at an outdoor music event: 
"Hot sunshine and a limit of one bottle per crowd user within the arena led to extremely large queues for water" (Observation: outdoor music event)

A number of interventions to respond to adverse weather and reduce the negative impact on crowd participants were observed. For example the provision of sheltered areas; outdoor heaters; sale or hiring of ponchos, umbrellas, blankets, sunscreen, hot food and beverages; and free water facilities. On another occasion, poor weather caused slippery ground that was dealt with using straw:

"Staff had to place straw down on the ground in areas that were very wet and muddy to prevent slips trips and falls" (Observation: outdoor music event)

\subsubsection{Stress, distractions and cultural norms}

The experience of 'stress' in crowd situations was discussed during focus groups, manifest as feelings of frustration, claustrophobia, vulnerability and intimidation:

"It's just the waiting [in a crowd] isn't it? The queuing, the waiting, and the frustration of getting what you want to get and waiting for people to get out of your way." (Older adult, female aged 68 years)

When no explanation is given about a delay, frustration and anxiety grows. However, the communication of information from positions of authority to crowd participants before and during delays and unexpected changes helped to reduce uncertainty and to provide reassurance. For example:

During a long queue to enter the event a security officer spoke to everyone in the queue, to explain the delay (due to the free food being provided on entry). The information update clarified the situation and reduced frustrations among crowd users" (Observation: conferences and exhibitions)

The positive influence of distractions including music, posters and refreshments were given as examples in the focus groups as ways of reducing boredom when waiting in a crowd.

Previous experience, prior expectations and cultural norms were discussed as being influential to satisfaction in a crowd. For example: 
"You'd have the expectation that there was going to be a lot of people there [at the crowd venue] so it's not going to be a surprise" (International students, female aged 26 years).

In a transportation situation, signage reminding pedestrians to "keep to the right" when using walkways or escalators at railway stations, or "begin queue here" and public announcements reminding passengers to "allow passengers to disembark before boarding the train", were helpful for emphasising cultural norms.

\subsection{Public order}

The maintenance of public order and good behaviour were discussed in the focus groups as being vital for crowd participant experience. The importance of friendly staff was raised, with this viewed as having a positive influence on the behaviour and mood of a crowd. It was considered reassuring to have staff and authoritative figures in place to respond to questions or give assistance. This was particularly the case for older participants:

"I think you do feel a bit more secure when there are security guards around" (Older adult: Female, aged 65).

The focus group discussions highlighted the importance of a proportionate relationship between the level of security and the behaviour of a crowd. It was described that a high level of security can suggest a higher level of danger, leading to feeling less safe.

During the observations, varying levels of security were seen. A number of occasions had a police presence (public security), whilst others were policed by private security organisations (independent from the national police service). In some circumstances there was both public and private security present, necessitating coordination between the two. When observing a football event with both a public and private security presence, the level of security felt very high (as compared with other crowds observed during this research):

"As antisocial behaviour in one area of the stadium grew, the number of private security officers surrounding the fans increased until police officers (public security) could also be seen managing the crowd behaviour. Although 
the level of security felt high, the antisocial behaviour was contained within one small area of the event" (Observation: outdoor sporting event)

At another crowd observation, a large public holiday celebration, there was a large police presence but at no point did this feel threatening:

"The police were friendly, responding more as marshals than figures of authority, providing directions, taking photos for crowd users, joining in and maintaining a positive atmosphere" (Observation: outdoor tourist event)

\section{Discussion}

In order to understand participant experience in crowds, this research conducted 5 focus groups with 35 participants and observed 55 events. The two qualitative studies provided different perspectives and complimentary sources of evidence on the factors influencing participant experience in crowds, summarised in Table 4. We believe that there is currently no comparable research that has examined crowd experience from the participants' perspective.

\subsection{Physical design of crowd spaces and facilities}

Previous research into the physical design of spaces and facilities has largely focused on safety and pedestrian movement. Attention to safety has aimed at avoiding situations described as 'clusters of people becoming trapped' (Sime, 1999), resulting from poor layout or poor organisation. As well as safety, the physical design of spaces in which crowds occur and design of facilities within such spaces, also directly affect the goal achievement, comfort and satisfaction of crowd participants. These important aspects of crowds have received much less attention in the research literature. Our research indicates how small alterations to the design of a venue or crowd location can have a significant impact on the experience of those attending or participating. Queuing, for example, can be a negative experience but, by implementing carefully considered queuing arrangements, the experience of participants can be improved. This can also have the added benefit for organisers and service providers of improving efficiency and avoiding clientele dissatisfaction. Guidance documents for those organising crowds (e.g. DCMS, 2008; EIF, 2014; HSE, 2014) state that 'orderly queuing' should be encouraged using stewards and 
barriers but does not provide specific, applicable examples of how the experience of queuing can be improved for those in the queue.

\subsection{Crowd movement}

The substantial body of research concerned with pedestrian flow modelling has largely been concerned with avoiding dangerous bunching and bottlenecks or efficient evacuation in emergency situations (Seyfried et al., 2006; Smith et al., 2009; Parisi et al., 2009; Qiu \& Hu, 2010; Still, 2013; Kim et al., 2015; Liu et al., 2016). There are limitations, however, with crowd simulations. Still (2013) highlights that there are a number of issues that are difficult to model using crowd simulation techniques, including the effects of mood, music and aggression on the behaviour of crowds.

It is clear that there are important safety considerations posed by crowds and movement of people within them. Our findings from focus groups and observations illustrate how crowd movement also affects participant enjoyment and satisfaction. Movement impeded by others in the way and unwelcome proximity between individuals are commonplace negative experiences in crowd situations. Likewise, persons with luggage, children, and wheelchairs may experience difficulties above a certain level of crowd density. All of these problems, however, can be avoided with design, planning and organisation that anticipates and caters for crowd participant needs.

\subsection{Communication of information: signage and wayfinding}

Despite evidence from the literature regarding the design and deployment of signage (e.g. Sime, 1999; Dogu \& Erkip, 2000; Rousek \& Hallbeck, 2011; Waterson et al., 2012; Hashim et al., 2014), inadequate signage was a frequent issue highlighted by focus groups and event observations in the present study. Event observations encountered clear, simple, easily identifiable signage, placed high above the crowd. As per The Purple Guide (EIF, 2014), ineffective signage and poor customer information were observed to result in crowd congestion and blockages. Passengers standing to read inappropriately positioned information, obstructing the flow of 
surrounding pedestrians, for example. As well as providing information and aiding wayfinding, effective signage can also have other benefits, such as relieving anxieties about getting lost.

\subsection{Comfort and welfare}

Key factors influencing comfort and welfare of participants in crowds were found to be the provision of welfare facilities, environmental comfort and sources of stress and anxiety. Welfare facilities need to be appropriate for the nature and size of a crowd and appropriately accessible (DCMS, 2008; EIF, 2014; HSE, 2014). Although providing adequate facilities for the number of participants is an obvious requirement, it was not always observed across event observations, emphasising the requirement to understand why this is, and how event planners decide upon the number and layout of facilities within a crowd in practice. Facilities including toilets are prominent in visitor complaints (Lee et al., 2007; Yoon et al., 2010). Research into festival events indicates that increasing the number of toilet facilities available, and regular cleaning, improves consumer satisfaction and thus customer loyalty.

For outdoor crowds, environmental comfort largely depends on the weather. The extent to which variance in weather is anticipated and catered for can affect 'crowd mood' (Berlonghi, 1995). Indoors, the nature of a crowd has a bearing on the acceptance of individuals in the crowd for hotter or cooler conditions, a rock concert versus an opera audience, for example. Cox et al. (2006) identified comfort as a possible moderating factor against experience of stress in crowds (Cox et al., 2006). These authors described how comfort might bear upon stress either by (i) stress arising from perceived crowding being exacerbated by discomfort or (ii) discomfort directly generating stress, irrespective of perceptions of crowdedness. Our findings, both from the focus groups and observations, corroborate the notion that a dynamic interplay exists between how a crowd situation is perceived by those within it and the tolerance of different aspects of that crowd situation. 


\subsection{Public order}

Our research has found that feeling safe and secure in a crowd situation is, not surprisingly, a high priority for crowd participants. Disorder in a crowd situation may be premeditated or deliberate, with some participants seeking to cause confrontation with rival groupings or those in authority. In circumstances where this might arise, policing, security and advance planning are important means of maintaining public order. In the crowd situation itself, it has been described how a positive relationship between the police and crowd participants leads to positive crowd behaviour and overall 'self-regulation' of the crowd (Reicher et al., 2004; Rosander \& Guva, 2012). Our observations noted the importance of friendly stewards in maintaining a good atmosphere and order in a crowd.

Disorder within a crowd may also evolve, with a deterioration of crowd 'mood'. Berlonghi (1995) referred to crowd catalysts that can influence the mood of a crowd. These were listed as: operational circumstances (e.g. no-show performers, sold out event); event activities (e.g. smoke, fireworks); performer's actions (e.g. violent gestures, offensive comments); spectator factors (e.g. consuming alcohol, throwing objects); security or police factors (e.g. use of unreasonable force, provocation); social factors (e.g. racial tension, rivalries); weather factors (e.g. heat, rain); natural disasters (earthquakes, flooding); man-made disasters (toxic chemicals, terrorist acts). In addition to their bearing on public order and safety, Berlonghi's crowd catalysts were also identified within our research as affecting the satisfaction of participants in crowds.

\subsection{Satisfaction and dissatisfaction}

We suggest that the nature of participant satisfaction in crowds can be compared to Herzberg's (1968) theory of job satisfaction, known as the motivation-hygiene theory. Herzberg suggested that the issues that contribute to job satisfaction (motivators) are separate and distinct from the factors that contribute to job dissatisfaction (hygienes). Therefore, job satisfaction and job dissatisfaction are not on the same continuum, and the absence of one does not assume the presence of the other. With regard to participant experience in crowds, our research similarly indicates that the factors that give rise to satisfaction are different from those that cause dissatisfaction. On the one hand, crowd satisfaction comes from involvement and enjoyment of an 
event or activity (e.g. sport, music, other celebration). On the other, dissatisfaction occurs from process factors, e.g. queuing, pushing and shoving, not being able to find your way or oppressive crowd density.

The implications of the analogy with Herzberg's theory are that attending to aspects that result in a negative experience for crowd participants may reduce dissatisfaction but is unlikely to result in satisfaction. Achieving satisfaction for crowd participants also needs explicit attention to 'motivators', with both motivators and hygienes needing to be considered in crowd planning and management side by side. An example from our observations that illustrates the interplay was at a large railway station, where eye catching sculptures (temporary and permanent) were seen giving pleasure to travellers. In the same location, pianos had been provided for anyone to walk up, play, listen and enjoy. Unfortunately, the positioning was such that people stopping to look and listen sometimes obstructed the pathway of pedestrians with luggage or hurrying to catch trains.

\subsection{International differences}

Although this study did not investigate international and cultural differences systematically, some observations can be made...

\subsection{Guidance on crowd planning and organisation}

A considerable body of guidance is available concerning the planning and organisation of crowd events. Principle sources in the UK are the Green Guide and Purple Guide, aimed at the organisers of sporting and music events respectively (DCMS, 2008; EIF, 2014), along with the Health \& Safety Executive's more general advice regarding crowd safety (HSE, 2014). In other countries, similar information exists, for example Work Safe Victoria (2007) in Australia and Cooper (2014) in the USA. This guidance includes advice on aspects featured within our findings: venue layout, queuing, monitoring capacity, pedestrian flow, signage, welfare facilities and antisocial behaviour. Almost exclusively, however, the emphasis is from an organisational planning and delivery viewpoint, focussing on regulatory, technical, welfare and safety facets. Referring back to the discussion above, the guidance 
addresses issues that may lead to dissatisfaction in a crowd situation but gives much less attention to factors influencing enjoyment and satisfaction. Our observations suggest that putting the guidance into practice happens with a good deal of variation, with apparently obvious considerations overlooked. We recorded crowd situations that were well planned and organised. Many, however, were not. Our study leads us to endorse Rowe and Ancliffe (2008) and Davies et al. (2014) in their call for a more ‘joined up' systems approach, in pursuit of improved crowd participant experience.

\section{Conclusions}

Crowd situations are commonplace and understanding the influences on participant experience is relevant to us all. This study aimed to identify aspects that contribute to a positive experience of crowds, as well as areas of crowd and event organisation that could be improved for the benefit of crowd participants. The findings highlight how aspects of the physical design of crowd spaces and facilities, crowd movement, communication of information, comfort and welfare and public order, affect participant experience. We observed many situations where participant experience could be improved, indicating a failure to give systematic consideration to important aspects in the planning and organisation of events or crowd situations. Crowd planning and organisation would benefit from a shift towards an ergonomics/human factors systems approach, embracing user (participant) centred design. Moreover, more could be done to understand how planners and organisers approach managing crowds, to understand what results in a well-organised event with a positive experience and, conversely, what leads to a poorly organised event and a negative experience for participants.

\section{References}

Altman, I. (1975). Introduction to the Environment and Social Behavior. Monterey, CA: Brooks/Cole Publishing Company, pp. 1-9.

Brown, S., \& Hutton, A. (2013). Developments in the real-time evaluation of audience behaviour at planned events. International Journal of Events and Festival Management, 4(1) 43-55. 
Bryman, A. (2004). Social Research Methods (3rd ed.). Oxford: Oxford University Press.

Berlonghi, A. E. (1995). Understanding and planning for different spectator crowds. Safety Science, 18(4), 239-247.

Braun, V., \& Clarke, V. (2006). Using thematic analysis in psychology. Qualitative Research in Psychology, 3(2), 77-101.

Challenger, R., Clegg, C. W., \& Robinson, M. A. (2010). Understanding crowd behaviours: Practical guidance and lessons identified. Emergency Planning College, London: Crown Copyright.

Challenger, R., \& Clegg, C. W. (2011). Crowd disasters: A socio-technical systems perspective. Contemporary Social Science, 6(3), 343-360.

Cooper, D.C. (Ed) (2014). The Event Safety Guide: A Guide to Health, Safety and Welfare at Live Entertainment Events in the United States. Event Safety Alliance of the USA, Inc. ISBN: 978-1-62914-761-1. Available at: http://eventsafetyalliance.org/. Accessed: 10.02.16

Cox, T., Houdmont, J., \& Griffiths, A. (2006). Rail passenger crowding, stress, health and safety in Britain. Transportation Research Part A: Policy and Practice, 40(3), 244-258.

Davis, M. C., Challenger, R., Jayewardene, D. N. W., \& Clegg, C. W. (2013). Advancing socio-technical systems thinking: A call for bravery. Applied Ergonomics, 45, 171-180.

Department for Culture Media and Sport (DCMS). (2008). Event Safety at Sports Grounds (5th Ed.). A guide to health, safety and welfare at sporting and similar events (the Green Guide), ISBN: 978-0-11-702074-0

Dogu, U., \& Erkip, F. (2000). Spatial factors affecting wayfinding and orientation: A case study in a shopping mall. Environment and Behavior, 32(6), 731-755. 
Drury, J., \& Stott, C. (2011). Contextualising the crowd in contemporary social science. Contemporary Social Science, 6(3), 275-288. Accessed 10.02.16

Eroglu, S. A., \& Harrell, G. D. (1986). Retail crowding: Theoretical and strategic implications, Journal of Retailing, 62, 347-363.

Eroglu, S. A., \& Machleit, K. A. (1990). An empirical study of retail crowding: Antecedents and consequences. Journal of Retailing, 66(2), 201.

Evans, G. W., \& Lepore, S. J. (1992), Conceptual and analytic issues in crowding research, Journal of Environmental Psychology, 12, 163-173.

Events Industry Forum (EIF) (2014). The Purple Guide to Health, Safety and Welfare at Music and Other Events. Available at: http://www.thepurpleguide.co.uk/. Accessed: 10.02 .16

Hashim, M. J., Salem, M., Alkaabi, K., \& Bharwani, S. (2014). Interpretation of wayfinding healthcare symbols by a multicultural population: Navigation signage design for global health, Applied Ergonomics, 45 503-509.

Hancock, P. A., \& Szalma, J. L. (2004). On the relevance of qualitative methods for ergonomics. Theoretical Issues in Ergonomics Science, 5(6), 499-506.

Health and Safety Executive. (2014). Manageing crowds safely: A guide for organisers at events and venues. Available at: http://www.hse.gov.uk/pubns/priced/hsg154.pdf. Accessed: 10.02.16

Hebb, D. O. (1972), Textbook of Psychology, (3rd Ed.), Sunders: Philadelphia. Herzberg F. (1968). One more time: how do you motivate employees? Harvard Business Review, 46(1), 53-62.

Hillsborough Independent Panel. (2012). Hillsborough Independent Panel: Disclosed Material and Report. Available at: http://hillsborough.independent.gov.uk

Hughes, R. L. (2003). The flow of human crowds. Annual Review of Fluid Mechanics, 35(1), 169-182. 
Johnson, C. W. (2008). Using evacuation simulations for contingency planning to enhance the security and safety of the 2012 Olympic venues. Safety Science, 46(2), 302-322.

Kim, K. M., Hong, S-P., Ko, S-J., \& Kim D. (2015). Does crowding affect the path choice of metro passengers? Transportation Research Part A, 77, 292-304.

Kreuger, R. A., \& Casey, M. A. (2000). Focus Groups. A practical guide for applied research. (3Ed.). London: Sage.

Liu, X., Song, W., Fu, L., \& Fang, Z. (2016). Experimental study of pedestrian inflow in a room with a separate entrance and exit. Physica A, 442, 224-238.

Lee, C., Lee, Y., Wicks, B.E. (2004). Segmentation of festival motivation by nationality and satisfaction. Tourism Management, 25(1), 61-70.

Lee, R. S. C., \& Hughes, R. L. (2007). Minimisation of the risk of trampling in a crowd. Mathematics and Computers in Simulation, 74(1), 29-37.

Lee, Y. K., Lee, C. K., Babin, B. J. (2007). Festivalscapes and patrons' emotions, satisfaction, and loyalty. Journal of Business Research, 61(1), 56-64.

Mowen, A. J., Vogelsong, H. G., \& Graefe, A. R. (2003). Perceived crowding and its relationship to crowd management practices at park and recreation events, Event Management, 8, 63-72.

Parisi, D. R., Gilman, M., \& Moldovan, H. (2009). A modification of the social force model can reproduce experimental data of pedestrian flows in normal conditions. Physica A: Statistical Mechanics and its Applications, 388(17), 3600-3608

Pons, F., Giroux, M., Mourali, M., \& Zins, M., (2015). The relationship between density perceptions and satisfaction in the retail setting: Mediation and moderation effects. Journal of Business Research.

Qiu, F., \& Hu, X. (2010). Modeling group structures in pedestrian crowd simulation. Simulation Modelling Practice and Theory, 18(2), 190-205. 
Reicher, S., Stott, C., Cronin, P., \& Adang, O. (2004). An integrated approach to crowd psychology and public order policing. Policing-an International Journal of Police Strategies \& Management, 27(4), 558-572.

Rosander, M., \& Guva, G. (2012). Keeping the peace - police behaviour at a mass event. Journal of Investigative Psychology and Offender Profiling, 9(1), 52-68.

Rousek, J.B. \& Hallbeck, M.S. (2011). Improving and analyzing signage within a healthcare setting, Applied Ergonomics, 42 771-784.

Rowe, I., \& Ancliffe, S. (2008). Guidance on designing for crowds - an integrated approach, CIRIA C675 (2008) RP761 ISBN: 978-0-86017-675-6, London: Classic House.

Rail Safety and Standards Board (2004), Crowd management at stations - a good practice guide. Available at: http://www.rssb.co.uk Accessed: 03.04.13

Ryan, C., Shih, S. Y., \& Huan, T. (2010). Theme parks and a structural equation model of determinants of visitor satisfaction - janfusan fancyworld, Taiwan. Journal of Vacation Marketing, 16(3), 185-199.

Seyfried, A., Steffen, B., \& Lippert, T. (2006). Basics of modelling the pedestrian flow. Physica A: Statistical Mechanics and its Applications, 368(1), 232-238.

Seyle, H. (1956). The Stress of Life. New York: McGraw-Hill.

Sime, J. D. (1999). Crowd facilities, management and communications in disasters. Facilities, 17(9), 313-324.

Singh, J. (1998). Striking a balance in boundary-spanning position: An investigation of unconventional influences of role stressors and job characteristics on job outcomes of salespeople. Journal of Marketing, 62(3), 69-86.

Smith, A., James, C., Jones, R., Langston, P., Lester, E., \& Drury, J. (2009). Modelling contra-flow in crowd dynamics DEM simulation. Safety Science, 47(3), 395-404. 
Smith, R. A. (1995). Density, velocity and flow relationships for closely packed crowds. Safety Science, 18(4), 321-327.

Stokols, D. (1972). On the distinction between density and crowding: Some implications for future research. Psychological Review, 79(3), 275-277.

Stott, C., Adang, O., Livingstone, A., \& Schreiber, M. (2008). Tackling football hooliganism: A quantitative study of Public Order, Policing and crowd psychology. Psychology, Public Policy, and Law, 14(2), 115-141.

Still, K. (2013). Introduction to Crowd Science, Taylor \& Francis Group, London. ISBN-13: 978-1-4665-7964-4

Sundstorm, E. (1978). Crowding as a Sequential Process: Review of Research on the Effects of Population Density of Humans, In: A. Baum and Y.M. Epstein (Eds) Human Responses to Crowding, Hillsdale, NJ: Erlbaum.

Waterson, P., Pilcher, C., Evans,S., \& Moore, J. (2012). Developing safety signs for children on board trains, Applied Ergonomics, 43 254-265.

Whiting, A., \& Nakos, G. (2008). Functional density and its impact on retail satisfaction in cross-cultural contexts: can crowded stores be a good thing for retailers. International Business: Research Teaching and Practice, 2(1).

Work Safe Victoria, (2007). Crowd control at venues and events: a practical occupational health and safety guide, 2nd Edition: Available at: https://www.worksafe.vic.gov.au/ data/assets/pdf file/0013/10354/crowd cont rol.pdf. Accessed: 10.02.16

Yildirim, K., \& Akalin-Baskaya, A. (2007). Perceived crowding in a café/restaurant with different seating densities. Building and Environment, 42(9), 3410-3417.

Yoon, Y., Lee, J., \& Lee, C. (2010). Measuring festival quality and value affecting visitors' satisfaction and loyalty using a structural approach. International Journal of Hospitality Management, 29(2), 335-342. 
Zhen, W., Mao, L., \& Yuan, Z. (2008). Analysis of trample disaster and a case study - Mihong bridge fatality in china in 2004. Safety Science, 46(8), 1255-1270. 


\section{Tables}

Table 1 Composition of focus group participants

\begin{tabular}{|l|c|c|c|c|}
\hline \multicolumn{1}{|c|}{ Focus Groups } & $\begin{array}{c}\text { Number of } \\
\text { participants }\end{array}$ & $\begin{array}{c}\text { Age } \\
\text { range } \\
\text { (lowest - } \\
\text { highest) }\end{array}$ & $\begin{array}{c}\text { Mean } \\
\text { Age }\end{array}$ & $\begin{array}{c}\text { Standard } \\
\text { Deviation }\end{array}$ \\
\hline $\begin{array}{l}\text { International } \\
\text { students }\end{array}$ & 6 & $22-27$ & 25.0 & 1.7 \\
\hline $\begin{array}{l}\text { Young } \\
\text { professionals }\end{array}$ & 8 & $25-34$ & 27.1 & 3.2 \\
\hline $\begin{array}{l}\text { Parents of young } \\
\text { children }\end{array}$ & 6 & $21-32$ & 27.3 & 3.9 \\
\hline Healthy adults & 8 & $40-55$ & 47.3 & 4.3 \\
\hline Older adults & 7 & $65-71$ & 67.7 & 2.4 \\
\hline TOTAL & 35 & $21-71$ & 39.5 & 17.0 \\
\hline
\end{tabular}


Table 2 Framework for participant observation based on focus group findings

\begin{tabular}{|c|c|c|}
\hline Theme & Area & Examples \\
\hline \multirow{3}{*}{$\begin{array}{l}\text { Physical design } \\
\text { of crowd spaces } \\
\text { and facilities }\end{array}$} & Venue layout & $\begin{array}{l}\text { Organisation of crowd, sectioning, one-way or contra } \\
\text { flow system, exit routes, view, car parking }\end{array}$ \\
\hline & Space available & Sufficient personal space \\
\hline & Goal achievement & $\begin{array}{l}\text { Able to fulfil intended purpose, conflicting goals, barriers } \\
\text { to goal achievement, competition between crowd } \\
\text { member }\end{array}$ \\
\hline \multirow[t]{4}{*}{$\begin{array}{l}\text { Crowd } \\
\text { movement }\end{array}$} & Time constraints & $\begin{array}{l}\text { Time considerations handled well, presence of } \\
\text { rushing/hurrying }\end{array}$ \\
\hline & Control & $\begin{array}{l}\text { Being in control of the situation, confusion, choice, } \\
\text { discretion }\end{array}$ \\
\hline & Individual factors & Physical height, age, special needs \\
\hline & Encumbrances & Trolleys, wheelchairs, pushchairs, bags, luggage \\
\hline \multirow{2}{*}{$\begin{array}{l}\text { Communication } \\
\text { of information }\end{array}$} & Navigation & Easy to find way around, disorientation, losing people \\
\hline & Communication & Signage, information availability, language barriers \\
\hline \multirow{8}{*}{$\begin{array}{l}\text { Comfort and } \\
\text { welfare }\end{array}$} & Welfare facilities & Seating, toilets, refreshments \\
\hline & $\begin{array}{l}\text { Environmental } \\
\text { factors }\end{array}$ & Weather, heat, vision, noise, odours, ventilation, pollution \\
\hline & Stress & $\begin{array}{l}\text { At ease, anxiety, frustration, vulnerability, intimidation, } \\
\text { claustrophobia }\end{array}$ \\
\hline & Motivation & $\begin{array}{l}\text { Wanting to be in the crowd, enjoyable purpose, financial } \\
\text { motivation }\end{array}$ \\
\hline & Preconceptions & $\begin{array}{l}\text { Prior experience and expectations, familiarity with } \\
\text { surroundings, cultural norms, stereotypes }\end{array}$ \\
\hline & Discretion & $\begin{array}{l}\text { Involvement at participants' discretion, unavoidable } \\
\text { experience of a crowd }\end{array}$ \\
\hline & Distraction & Presence of factors that distract from the crowd situation \\
\hline & Social aspects & Accompaniment of friends, lonely in crowd \\
\hline \multirow[t]{3}{*}{ Public order } & Safety and security & $\begin{array}{l}\text { Feeling safe, slip, trip and fall hazards, trampling risk, } \\
\text { violence }\end{array}$ \\
\hline & Behaviour & Appropriate, polite, antisocial, pushing, jostling \\
\hline & Mood & Anticipation, atmosphere, excitement, boredom, hostility \\
\hline
\end{tabular}


Table 3 Composition of crowd situations observed

\begin{tabular}{|l|c|}
\hline Crowd type & Number \\
\hline Music event & 9 \\
\hline Sporting event & 6 \\
\hline Theatre event & 8 \\
\hline Participatory event & 4 \\
\hline Tourist event & 5 \\
\hline Conferences and exhibitions & 7 \\
\hline Retail & 8 \\
\hline Transport hub & 8 \\
\hline Total & $\mathbf{5 5}$ \\
\hline
\end{tabular}


Table 4 Primary factors contributing to crowd participant experience

\begin{tabular}{|c|c|c|}
\hline $\begin{array}{l}\text { Emergent } \\
\text { themes }\end{array}$ & Negative experience & Positive experience \\
\hline \multirow[t]{2}{*}{$\begin{array}{l}\text { Physical design } \\
\text { of crowd } \\
\text { spaces and } \\
\text { facilities }\end{array}$} & $\begin{array}{l}\text { Venue layout: layout of facilities that } \\
\text { increase competition between crowd } \\
\text { participants; blocked pathways; } \\
\text { bottlenecks }\end{array}$ & $\begin{array}{l}\text { Venue design: sectioned areas; clear } \\
\text { exit routes; seating; unimpeded } \\
\text { pedestrian flow }\end{array}$ \\
\hline & $\begin{array}{l}\text { Queuing: no clear queuing system; } \\
\text { grouping rather than one organised } \\
\text { queue (difficult for serving staff to } \\
\text { determine who is next in the queue); } \\
\text { competition between crowd participants } \\
\text { - frustration, pushing and shoving, } \\
\text { delays; no information on position in } \\
\text { queue and waiting times }\end{array}$ & $\begin{array}{l}\text { Queuing: transparent and fair queuing } \\
\text { systems (designed to allow serving } \\
\text { staff to identify easily who is next in the } \\
\text { queue); layout of facilities to optimise } \\
\text { associated queuing; waiting times } \\
\text { highlighted; specified entry times } \\
\text { provided }\end{array}$ \\
\hline \multirow[t]{3}{*}{$\begin{array}{l}\text { Crowd } \\
\text { movement }\end{array}$} & $\begin{array}{l}\text { Calculating capacity: based on safety } \\
\text { but not accounting for comfort levels; } \\
\text { hot and sweaty environment; increased } \\
\text { competition between crowd participants }\end{array}$ & $\begin{array}{l}\text { Calculating capacity: based on comfort; } \\
\text { ticketed event; ticketed areas to } \\
\text { manage capacity within venue; } \\
\text { allocated space per crowd user (i.e. } \\
\text { individual seats) }\end{array}$ \\
\hline & $\begin{array}{l}\text { Pedestrian Flow: obstacles in } \\
\text { walkways; crossing walkways, causing } \\
\text { unwanted encounters and frustration; } \\
\text { layout of facilities and queuing systems } \\
\text { impeding pedestrian flow; mass } \\
\text { departure from a crowd event poorly } \\
\text { managed }\end{array}$ & $\begin{array}{l}\text { Pedestrian Flow: ample spacing for } \\
\text { pedestrians to pass one another; } \\
\text { contra-flow to avoid encounters } \\
\text { between pedestrians; unobstructed } \\
\text { walkways allowing users to move } \\
\text { within crowd without impedance and } \\
\text { bottlenecks; alternative routes to avoid } \\
\text { overcrowding indicated in advance }\end{array}$ \\
\hline & $\begin{array}{l}\text { Encumbrances: personal space } \\
\text { insufficient for crowd participants and } \\
\text { pushchair/luggage/wheelchair; } \\
\text { assistance required }\end{array}$ & $\begin{array}{l}\text { Encumbrances: sufficient space for } \\
\text { crowd user and } \\
\text { pushchair/luggage/wheelchair; wide } \\
\text { walkways and accessible welfare } \\
\text { facilities; luggage storage }\end{array}$ \\
\hline $\begin{array}{l}\text { Communication } \\
\text { of information }\end{array}$ & $\begin{array}{l}\text { Signage and wayfinding: absence of } \\
\text { signage; poor visibility; unclear } \\
\text { signage; font size too small to read } \\
\text { (e.g. particularly older users, or } \\
\text { reduced vision); inappropriate } \\
\text { positioning; flimsy signage; language } \\
\text { barriers }\end{array}$ & $\begin{array}{l}\text { Signage and wayfinding: signage } \\
\text { tailored to needs and goals; large, high } \\
\text { overhead; viewing position not } \\
\text { obstructing pedestrian flow; clear; large } \\
\text { font size; fixed signage; use of } \\
\text { pictograms; public announcements of } \\
\text { information }\end{array}$ \\
\hline \multirow[t]{3}{*}{$\begin{array}{l}\text { Comfort and } \\
\text { welfare }\end{array}$} & $\begin{array}{l}\text { Welfare facilities: insufficient provision } \\
\text { for crowd numbers; unhygienic; layout } \\
\text { creating competition between crowd } \\
\text { participants; long delays }\end{array}$ & $\begin{array}{l}\text { Welfare facilities: convenient location } \\
\text { throughout venue; adequate numbers } \\
\text { during peak times; fair queuing } \\
\text { systems; hygienic (i.e. toilet facilities } \\
\text { cleaned regularly) }\end{array}$ \\
\hline & $\begin{array}{l}\text { Environmental comfort: uncomfortable; } \\
\text { oppressive heat; cold and wet (i.e. } \\
\text { outdoor events); no areas to shelter; } \\
\text { umbrellas disrupting the view of other } \\
\text { spectators }\end{array}$ & $\begin{array}{l}\text { Environmental comfort: comfortable; } \\
\text { free water facilities; sunscreen to buy } \\
\text { during sunshine; raincoat to buy during } \\
\text { rain; warm drinks to buy when cold; } \\
\text { sheltered areas during cold and rain }\end{array}$ \\
\hline & $\begin{array}{l}\text { Stress, distractions, and cultural norms: } \\
\text { boredom; frustrations and reduced } \\
\text { enjoyment; assuming all users (i.e. } \\
\text { tourists) understand unwritten rules } \\
\text { and behavioural norms (queuing } \\
\text { behaviours; personal space } \\
\text { preferences); no prior warning of } \\
\text { delays }\end{array}$ & $\begin{array}{l}\text { Stress, distractions, and cultural norms: } \\
\text { interaction between organisers and } \\
\text { crowd participants; music, posters and } \\
\text { refreshments whilst queuing or waiting } \\
\text { in a crowd; signage to highlight "keep } \\
\text { to the right" etc.; public announcements } \\
\text { to inform passengers.(i.e. allow } \\
\text { passengers off trains before getting on, } \\
\text { explain delays) }\end{array}$ \\
\hline
\end{tabular}




\begin{tabular}{|l|l|l|}
\hline $\begin{array}{l}\text { Emergent } \\
\text { themes }\end{array}$ & \multicolumn{1}{|c|}{ Negative experience } & \multicolumn{1}{c|}{ Positive experience } \\
\hline Public order & $\begin{array}{l}\text { Behaviour: presence of antisocial } \\
\text { behaviour; rude staff; heavy handed } \\
\text { security enhancing tension in the } \\
\text { crowd; feeling unsafe and at risk of } \\
\text { harm }\end{array}$ & $\begin{array}{l}\text { Behaviour: positive experience for the } \\
\text { majority; individuals causing antisocial } \\
\text { behaviour removed (swearing, racist } \\
\text { chanting and alcohol abuse); level of } \\
\text { security matched to level of threat of } \\
\text { antisocial behaviour; learning from } \\
\text { previous incidents in the same or } \\
\text { similar events; incidents logged to aid } \\
\text { future event planning }\end{array}$ \\
\hline
\end{tabular}




\section{Figures}

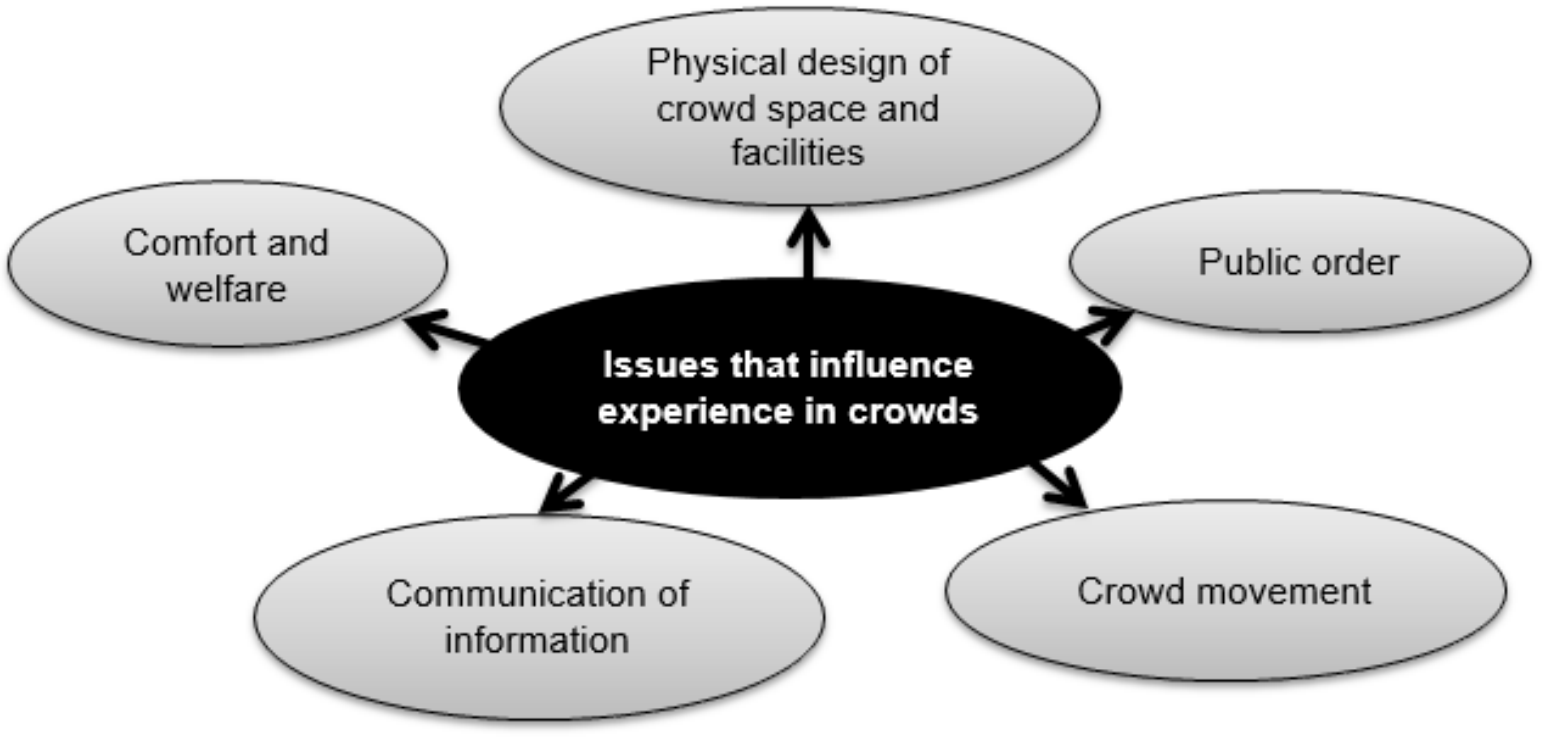

Figure 1 Key themes drawn from the data 


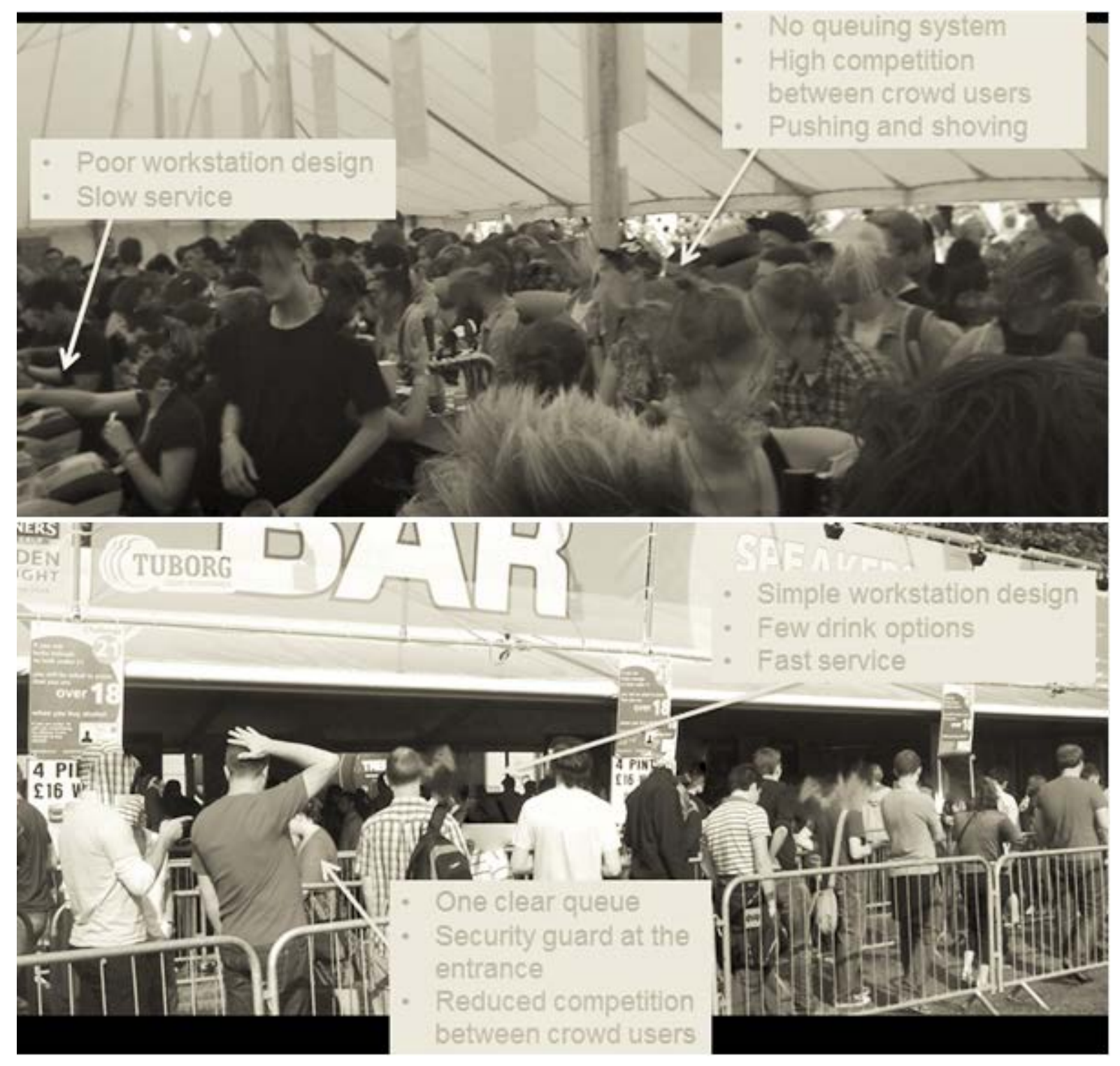

Figure 2 Examples of different queue management strategies seen during crowd observations 